\title{
Computed Tomography Evaluation of Tibial Plateau Fracture and Classification by Schatzker System
}

\author{
Umamaheshwari Basavaraju ${ }^{1}$, Shruti Mankani ${ }^{2}$, Nanjaraj Chakenalli Puttaraj ${ }^{3}$, N.L. Rajendrakumar ${ }^{4}$, Kavya \\ Shree ${ }^{5}$, Sowmya Jagadish ${ }^{6}$ \\ ${ }^{1}$ Associate professor, Department of Radiodiagnosis, ${ }^{2}$ Resident, Department of Radiodiagnosis, ${ }^{3}$ Professor and Dean \& \\ Director, Department of Radiodiagnosis, ${ }^{4}$ Professor and HOD, Department of Radiodiagnosis, ${ }^{5}$ Resident, Department of \\ Radiodiagnosis, ${ }^{6}$ Resident, Department of Radiodiagnosis, Mysore Medical College and Research Institute, India
}

Corresponding author: Shruti Mankani, Room No 27, PG Hostel for Womens, Opposite Nanjaraj Bahudur Chatra, Vinobha Road, Mysuru 570001, India

DOI: http://dx.doi.org/10.21276/ijcmsr.2018.3.4.8

How to cite this article: Umamaheshwari Basavaraju, Shruti Mankani, Nanjaraj Chakenalli Puttaraj, N.L. Rajendrakumar, Kavya Shree, Sowmya Jagadish. Computed tomography evaluation of tibial plateau fracture and classification by schatzker system. International Journal of Contemporary Medicine Surgery and Radiology. 2018;3(4):D29-D32.

\section{A B S T R A C T}

Introduction: Tibial plateau fractures are usually associated with high energy trauma. Computed tomography evaluation and classification of fractures by Schatzkers system helps in pre-operative planning and management. Study aimed to enumerate the role of computed tomography in tibial plateau fractures and its classification assisting in treatment management.

Material and methods: A prospective study of computed tomographic assessment of tibial plateau fractures was done in the department of Radio-diagnosis, Mysore Medical College and Research Institute. Age, gender distribution, mode of injury, affected limb and further classification of fractures by Schatzker system and management were recorded. The results were tabulated and evaluated by Microsoft excel 2010.

Results: The study included 30 patients with tibial plateau fracture evaluated with plain computed tomography. Majority of patients were males, most between 30 to 35 years, the left limb is injured more commonly than the right limb, with most common causative factor being the motor vehicle accident. Further Schatzker's type II fracture was most commonly seen. Out of 30 patients, 11 with complex fractures required open reduction and internal fixation done as a staged procedure, 14 were treated with minimally invasive plate osteosynthesis (MIPO) technique, 2 patients were managed conservatively with strict immobilization, 2 patients were referred to higher center and 1 patient died due to associated grievous injury.

Conclusion: Tibial plateau fractures occur as a result of high energy trauma, evaluation and classification of fractures by computed tomography can help in proper planning of management of fractures in accordance with severity of fractures.

Key words: Complex Fractures, Articular Surface Incongruity, Ligamentous Instability, Pre-Operative Planning, Management, Minimally Invasive Plate Osteosynthesis

\section{INTRODUCTION}

Tibial plateau fractures are rare, account for about $1.2 \%$ of all fractures. These delineate a wide range of fractures with severity ranging from non-displaced closed fracture which can be managed conservatively to more complicated fractures extending along the metaphysis requiring emergent surgical management. ${ }^{1}$

In young patient, fractures are more commonly due to high energy trauma, however in older patient can occur even with less severe injury. Plain radiograph can diagnose these fractures, but computed tomography can better evaluate the complexity of fracture pattern, hence used before preoperative planning. ${ }^{2}$ Study aimed to enumerate the role of computed tomography in tibial plateau fractures and its classification assisting in treatment management.

Material and methods:

One year prospective study was conducted from March 2017 to April 2018. The study included the patients referred to Department of Radiodaignois for computed tomography evaluation of tibial plateau fractures. All the patient with history of trauma and plain radiography depicting tibial plateau fracture were included in the study (figures 1-6). Patient with systemic disorder like osteoporosis and other risk factors are excluded from the study. Detailed history and written consent of the patient was taken before hand.

The patients were subjected to computed tomography examination using standard knee protocol. Patient positioned in dorsal decubitus with knee flexed to 15 degrees, affected limb was maintained still and contralateral leg folded. Acquisition was done $1 \mathrm{cms}$ above the patella to $1 \mathrm{cms}$ below the tibial tuberosity and expanded if necessary to cover the entire fracture leg. Axial $3 \mathrm{~mm}$ sections were acquired and formatting was done to $1 \mathrm{~mm}$ section in sagittal and coronal planes in both soft tissue and bone window. The 
study was done to evaluate the age distribution, mode of injury, classification according to Schatzker system and to determine the further management. The study was approved by the Institutional Ethics and Research Committee.

\section{STATISTICAL ANALYSIS}

The result of the study were tabulated and evaluated descriptively by Microsoft excel 2010.

\section{RESULTS}

In our study, patients aged between 10 to 60 years were include with the mean age of 37.6 years, males(73.3\%) more commonly affected than females $(27.7 \%)$, because of greater exposure to risk situations. Most common mode of injury was motor vehicle crash injury (46.7\%), followed by fall from height (20\%) and car crash and run over injury (13.3\%) (table-1).

Schatzkers type II accounted for most common type of fracture constituting around 36.7\%. Type $\mathrm{V}$ fractures accounted for $20 \%$, was the next most common type. Among the limb affected 16 (53.3\%) patients had left limb injury and $14(47.7 \%)$ on right side. Associated injuries were found in 18 (60\%) patients (table-2).

Out of 30 patients, 11 with complex fractures required open

\begin{tabular}{|l|c|c|}
\hline Age & Number & Percentage \\
\hline $0-10$ & 0 & 0 \\
\hline $10-20$ & 2 & 6.7 \\
\hline $20-30$ & 5 & 16.7 \\
\hline $30-40$ & 8 & 26.7 \\
\hline $40-50$ & 13 & 43.3 \\
\hline $50-60$ & 2 & 6.7 \\
\hline \multicolumn{2}{|c|}{ Table-1: Age distribution of patients } \\
\hline
\end{tabular}

\begin{tabular}{|l|l|c|c|}
\hline Variable & Category & Number & \% \\
\hline \multirow{3}{*}{ Sex } & Male & 22 & 73.3 \\
\cline { 2 - 4 } & Female & 8 & 26.7 \\
\hline Mechanism of injury & Right & 14 & 46.7 \\
\cline { 2 - 4 } & Left & 16 & 53.3 \\
\cline { 2 - 4 } & Fall from height & 6 & 20.0 \\
\cline { 2 - 4 } & Motorcycle crash & 14 & 46.7 \\
\cline { 2 - 4 } & Run over & 4 & 13.3 \\
\cline { 2 - 4 } & Car crash & 4 & 13.3 \\
\cline { 2 - 4 } & Fight & 1 & 3.3 \\
\cline { 2 - 4 } & Football & 1 & 3.3 \\
\hline Associated injury & Present & 18 & 60 \\
\cline { 2 - 4 } & Absent & 12 & 40 \\
\hline \multicolumn{2}{|c|}{ Table-2: Sample characteristics } \\
\hline
\end{tabular}

\begin{tabular}{|l|c|c|c|}
\hline Scale & Level & Number & Percentage \\
\hline Schatzker classification & $\mathrm{I}$ & 3 & 10 \\
\cline { 2 - 4 } & $\mathrm{II}$ & 11 & 36.7 \\
\cline { 2 - 4 } & $\mathrm{III}$ & 3 & 10 \\
\cline { 2 - 4 } & $\mathrm{IV}$ & 5 & 16.7 \\
\cline { 2 - 4 } & $\mathrm{V}$ & 6 & 20 \\
\cline { 2 - 4 } & $\mathrm{VI}$ & 2 & 6.7 \\
\hline \multicolumn{3}{|c|}{ Table-3: Classification of tibial plateau fractures } \\
\hline
\end{tabular}

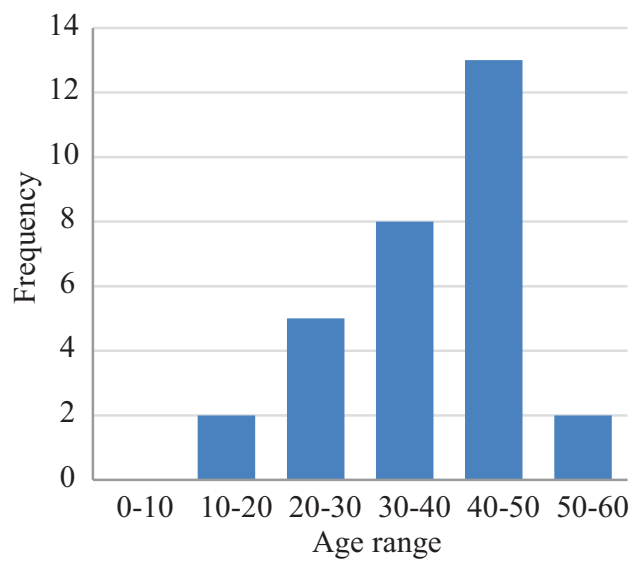

Graph-1: Frequency distribution by age range

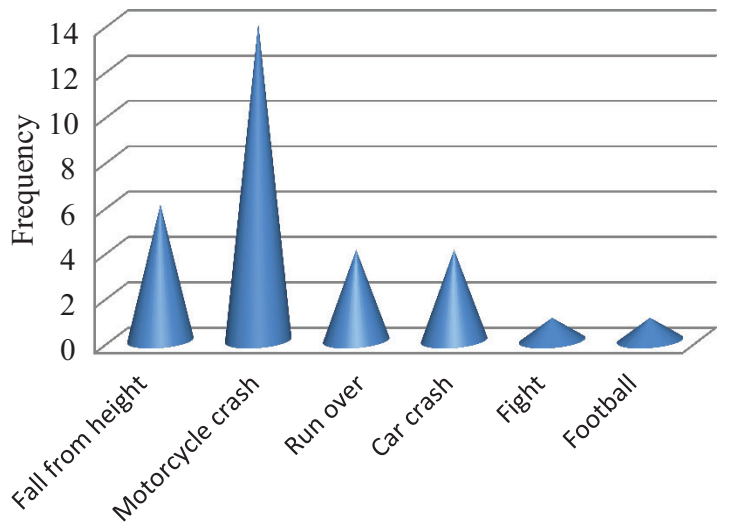

Mechanism of injury

Graph-2: Relative distribution of mechanism of injury

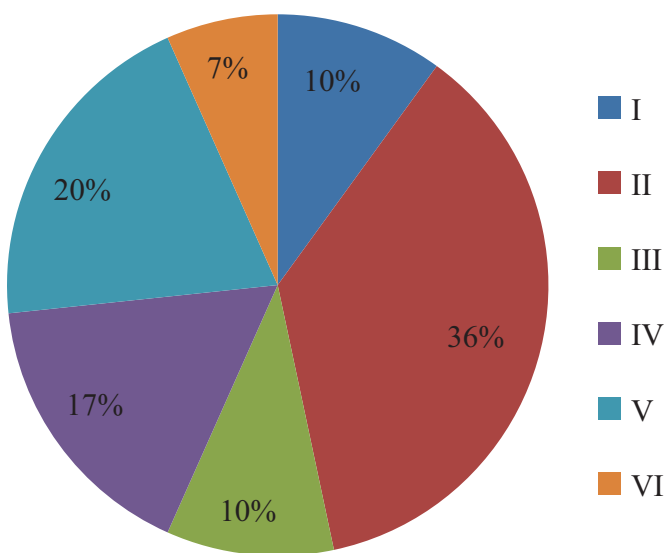

Graph-3: Distribution of patients according to Schatzker classification

reduction and internal fixation done as a staged procedure, 14 were treated with minimally invasive plate osteosynthesis (MIPO) technique, 2 patients were managed conservatively with strict immobilization, 2 patients were referred to higher center and 1 patient died due to associated grievous injury.

Tibial plateau fractures are transient intra-articular fractures of weight bearing joint which can result in joint surface incongruity and ligamentous instability. Effective surgical management can achieve reduction of joint surface,

\section{DISCUSSION}



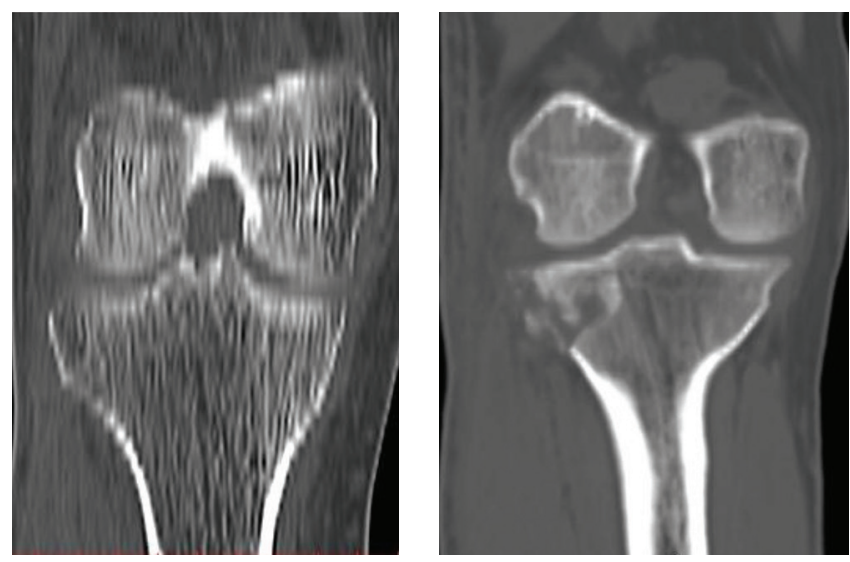

Figure-1: 50-year-old man who history of fall from height. Coronal CT image shows no depression of the tibial plateau, a finding consistent with a type I fracture. The fracture was managed conservatively; Figure-2: 42-year-old man after fall from bike. Coronal CT image shows $4 \mathrm{~mm}$ of depression, a finding indicative of a type II fracture. The fracture was treated with minimally invasive plate osteosynthesis.
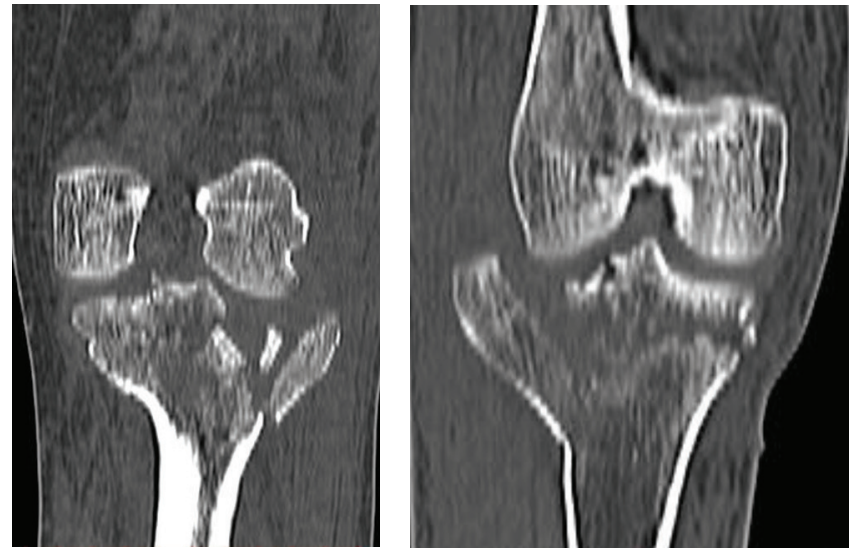

Figure-3: 45-year-old woman who was in a high-speed motorcycle collision. Coronal CT image shows the medial tibial plateau fracture and medial subluxation, a type IV fracture. Initially, the fracture was reduced with placement of a spanning external fixator because of significant soft-tissue swelling and concern about vascular compromise. Surgical reduction and internal fixation were performed once the swelling had resolved; Figure-4: Type V fracture in a 60-yearold man with history of fall from building. Coronal CT image shows the bicondylar split fracture. Physical examination showed no evidence of neurovascular compromise. Initially, the fracture was reduced with placement of a spanning external fixator because of significant soft-tissue swelling. Once the swelling had resolved, definitive surgical reduction and internal fixation were performed with double buttress plating.

permit early mobilization of patient as well as reduces post-operative complications. This can be achieved when a surgeon understands the severity and type of fracture which aids in deciding the management. ${ }^{3,4}$ The above results were similar to study done by Albuquerque et all and A. M. F. El Kharboutly et all. ${ }^{3,4}$

Tibial plateau fractures are inherent complex fractures, which produce difficulty in classification on the plain radiography

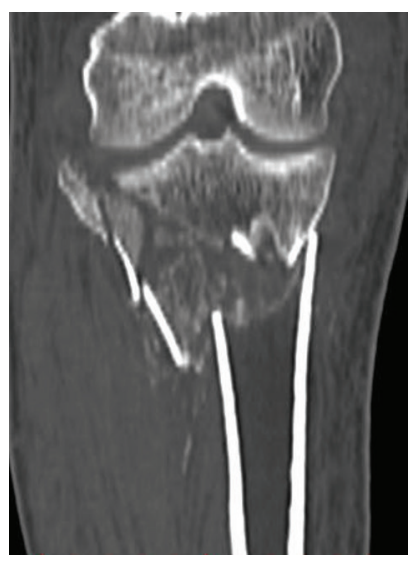

Figure-5: Type VI fracture in a 43-year-old man history of motor vehicle. Coronal CT image shows the lateral split fracture component of the type VI tibial plateau fracture. Initially, the fracture was reduced with placement of a spanning external fixator because of significant soft-tissue swelling. Once the swelling had resolved, definitive surgical reduction and internal fixation were performed.

regardless of the system used. Computed tomography is better than plain radiograph for evaluation of tibial plateau fractures and has been accepted to be the imaging modality for pre-operative planning. ${ }^{5}$

Various classification system described for tibial plateau fractures but most commonly used are Schatzker ${ }^{6}$, Hohl and Moore $^{7}$ and Arbeitsgemeinschaftfur Osteosynthesefragen (AO). ${ }^{8}$ Computed tomography has provided a good intra and inter-observer reliability for all the three classification systems. Schatzker is most commonly used in clinical practice because of its ease of use. ${ }^{9}$

In 1979 Schatzker et al. from AP radiographs presented their classification system (table-3) and divided tibial plateau fractures into 6 groups based on fracture pattern, which helped to direct operative versus non-operative treatment. ${ }^{1,2,6,9,12}$

Type I: split fracture of the lateral tibial plateau

Type II: split depression of the lateral tibial plateau

Type III: central depression of the lateral plateau

Type IV: split of the medial tibial plateau

Type $\mathrm{V}$ bicondylar tibial plateau fracture

Type VI: dissociation between the metaphysis and diaphysis In our study computed tomography evaluation and classification of tibial plateau fractures with Schatzker system has provided orthopedic surgeon a better view of fracture planes as well as the severity and assisted in pre-operative planning.

Rufi et al. and Martijin et al. also corroborated computed tomography is superior to plain radiography for assessment of tibial plateau fractures. ${ }^{10,11}$

Our study also agreed with study done by Zelster et al, who stated that Schatzkers system is frequently used in practice because its wide acceptance and ease of use. Schatzkers classification grades the fracture with increasing severity which indicated both impact of injury and increasingly the worse prognosis. ${ }^{12}$

Cross sectional imaging results can change the operative management by accurate description of fracture pattern, depression and displacement of fracture fragments, which 
are most important factor in management. ${ }^{13}$

Depression of $>6 \mathrm{~mm}$ and widening of $>5 \mathrm{~mm}$ increases the likelihood of injury to lateral meniscus. Depression and widening $>8 \mathrm{~mm}$ is demonstrates associated injury to medial meniscus. ${ }^{14}$

Type IV fractures are associated with popliteal artery and peroneal nerve injury. ${ }^{15}$ Moore et all stated type $\mathrm{V}$ is more commonly associated with soft tissue injury and type VI fractures are more prone for compartment syndrome. ${ }^{16}$ CT can demonstrate the ligament injury with $80 \%$ sensitivity and $98 \%$ specificity. Only $2 \%$ are missed on CT, which on MRI evaluation had partial or complete tears. ${ }^{16,17}$

Partial articular fractures are managed with minimally invasive osteosynthesis when possible, complex articular fractures requires surgical management with open reduction and internal fixation. Osteoarthritis is common complication following treatment. ${ }^{18}$

\section{Limitation}

Inability to evaluate the associated intra-articular injuries. MRI is the modality of choice for depiction of meniscal and ligament injury.

\section{CONCLUSION}

Computed tomography is widely used as an imaging modality of choice by most orthopedic surgeon for evaluation tibial plateau fractures. It is used in pre-operative planning and also aids in surgical management. Though MRI can depict associated soft tissue injury, usually not recommended because of long waiting time, strict immobility and sedation required in unco-operative patients.

\section{REFERENCES}

1. Zeltser DW, Leopold SS. Classifications in brief Schatzker classification of tibial plateau fractures. Clin Orthop Relat Res 2013;471(2).

2. Thomas $\mathrm{CH}$, Athanasiov A, Wullschleger M, Schuetz M.Current concepts in tibial plateau fractures. Acta Chir OrthopTraumatol Cech. 2009;76(5):363-73.

3. Wicky S, Blaser PF, Blanc CH, Leyvraz PF, Schnyder P, Meuli RA. Comparison between standard radiography and spiral CT with $3 \mathrm{D}$ reconstruction in the evaluation, classification and management of tibial plateau fractures. Eur Radiol 2000;10(8):1227-32.

4. A.M.F. E1 Kharboutly. MDCT in assessment of tibial plateau fractures. ejrnm. 2015.05.011

5. Chan PS, Klimkiewicz JJ, Luchetti WT, Esterhai JL, KneelandJB, Dalinka MK, Heppenstall RB. Impact of CT scan on treatmentplan and fracture classification of tibial plateau fractures.J Orthop Trauma. 1997; 11(3):484-489.

6. Schatzker J, McBroom R, Bruce D. The tibial plateau fracture. The Toronto experience 1968-1975. Clin Orthop Relat Res 1979;138(5):94-104.

7. Hohl M, Moore TM. Articular fractures of the proximal tibia. In: Evarts CM, editor. Surgery of the musculoskeletal system. 2nd ed., New York: Churchill Livingstone; 1990.

8. Mu"ller ME, Nazarian S, Koch P, Schatzker J. The comprehensive classification of fractures in long bones. Berlin: Springer- Verlag; 1990.
9. Brunner A, Horisberger M, Ulmar B, Hoffman A, Babst R. Classification systems for tibial plateau fractures: does computed tomography scanning improve their reliability? Injury. 2010;41(1):173-178.

10. Rafii M, Lamont JG, Firooznia H. Tibial plateau fractures: CTevaluation and classification. Crit Rev Diagn Imaging.1987;27(2):91-112.

11. Martijn AJ, Holla M, Biert J, Kampen A. The value of a CT scancompared to plain radiographs for the classification andtreatment plan in tibial plateau fractures. Emerg Radiol.2011;18(3):279-83.14

12. Markhardt BK, Gross JM, Monu JU. Schatzker classification oftibial plateau fractures: use of CT and MR imaging improvesassessment. Radiographics. 2009;29(4):585-597.

13. Macarini L, Murrone M, Marini S, Calbi R, Solarino M, Moretti B. Tibial plateau fractures: evaluation with multidetector-CT. Radiol Med 2004;108(5-6):503-514.

14. Gardner MJ, Yacoubian S, Geller D, Pode M, Mintz D, HelfetDL, Lorich DG. Prediction of soft-tissue injuries in Schatzker II tibial plateau fractures based on measurements of plain radiographs.J Trauma. 2006;60(3):319-323; discussion 324.

15. Canale TS. Tibial plateau fracture. In: Canale ST, ed. Campbell's operative orthopaedics. 10th ed. Philadelphia, Pa: Mosby, 2006; 3146-3161.

16. Moore TM, Patzakis MJ, Harvey JP. Tibial plateau fractures: definition, demographics, treatment rationale, and long-term results of closed traction management or operative reduction. J Orthop Trauma 1987;1(2):97119.

17. Mui LW, Engelsohn E, Umans H. Comparison of CT and MRI in patients with tibial plateau fracture: can CT findings predict ligament tear or meniscal injury? Skeletal Radiol 2007;36(2):145-151.

18. Charalambous CP, Tryfonidis M, Alvi F, Moran M, Fang C, Samaraji R, Hirst P. Inter- and intraobserver variation of the Schatzker and AO/OTA classifications of tibial plateau fractures and a proposal of a new classification system. Ann R Coll Surg Engl. 2007;89(5):400-404

\section{Source of Support: Nil; Conflict of Interest: None}

Submitted: 25-09-2018; Accepted: 29-10-2018; Published online: 13-11-2018 